\title{
GEOCRONOLOGIA Pb-Pb EM ZIRCÃO (MÉTODO DE EVAPORAÇÃO) DAS ROCHAS DO EMBASAMENTO DO SETOR MERIDIONAL DO CINTURÃO ARAGUAIA - REGIÃO DE PARAÍSO DO TOCANTINS (TO)
}

\section{SILVIA HELENA DE SOUZA ARCANJO \& CANDIDO AUGUSTO VELOSO MOURA}

\begin{abstract}
GEOCHRONOLOGY OF THE BASEMENT ROCKS OF THE SOUTHERN PORTION OF THE ARAGUAIA BELT - PARAISO DO TOCANTINS REGION (TO) Recent geochronological studies of the basement olthogneisses of the northern region of the Araguaia bel DO TOCANTINSREGION (TO) Recent geochronological studies of the basement or showed the occurrence of both Archean (2.85 Complex, the younger were named the Cantão Gneiss. In the southern portion of the Araguaia bell, the basene metavulcanic-sedimentary rocks, tonalitic, calc-silicate, and alkaline gneisses, and granitic rocks. All of these sequences have been considered as Archean in age, although no geochronological data are available to test this hypothesis. The metavolcanic-sedimentary rocks are included in Archean in age, although no gro granitic rocks are represented by the Serrote and Matança granites. The tonalitic and calc-silicate gneisses in the Rio do Co alkaline gneisses in the Monte Santo Suite.

were grouped with Colmeia and Rio dos Mangues Complexes, and the alkaline gneisses in the Monte Santo Sule. These gneisses were investigated geochronologically by single zircon Pb-evaporation methods in order to define their stratigraphic interelationships, and to contribute to a greater understanding of the geological evolution of this crustal segment. The single zircon ages of the tonalitic and calc-silicate gneisses range between 1.8 and 2.1 Ga. An age of $1.85 \mathrm{Ga}$. published for the Serrote Granite, indicate the widespread Estrela (Monte Santo Suite). These data, along with the single zircon age of 1.85 Ga. published for the existence of Arquean sequences in this recurrence of Proterozoic rocks in the basement of the southern part of Araguala belt. However, the existence of

region can not be discarted since the volcanic-sedimenth the Colmeia Complex was not confirmed, so these gneisses have been grouped with The correlation of tonalitic and calc-silicate gneisses with it is suggested that a significant part of the basement of the southern portion of the the Early Proterozoic Rio dos Mangues Complex. Thus, its the Early Proterozoic. The alkaline gneisses are Araguaia belt may represent a younger crustal segment accreted to the Amazon Craton during the Early Proterozolic interpreted as representative of the alkaline magmatism associated with the extensional phase that developed, in the published age of $510 \mathrm{Ma}$ for the Matança Granite may date the final phase of this deformation.
\end{abstract}

Keyvords: Araguaia belt, Geoc/wonology, Pb-Pb Zircon.

RESUMO Estudos geocronológicos realizados nos ortognaisses do embasamento no segmento setentrional do Cinturão Araguaia revela作 do Arag no Complos tonalíticos, calciossilicáticos e alcalinos, Araguaia, as sequências do embasamento compreendem rochas metavicano de idade arqueana embora não existam dados geocronológicos além de rochas graníticas associadas. Todo esse conjunto tem sido considerado de idade arqueana embora não existam dados geocrono gán comprovando essa hipótese. As rochas metavulcano-sedimentares compõem o Grupo Rio do Coco e as rochas graníticas são representadas pelos granitóides Serrote e Matança. Os gnaisses tonalíticos e calciossilicál

que os gnaisses alcalinos foram agrupados na Suíte Monte Santo. Esses gnaisses foram investigadas geocronologicamente através do método de evaporação de chumbo (Pb) em monocristais de zircão visando definir as relações estratigráficas entre os mesmos, contribuindo, dessa forma, para o entendimento da evolução geologica desse segmento crustal Para os gnaisses tonalíticos e calciossilicáticos, as idades obtidas em zircôes situaram-se entre 1,8 e 2,1 Ga. Para os gnaisses sieníticos de Serra da Estrela (Suíte Monte Santo) obteve-se uma idade em torno de 1,0 Ga. Esses dados, juntamente com a idade de 1,85 Ga publicada de Serra da Esco de rochas proterozóicas no embasamento da porção meridional do Cinturão Araguaia. para o Granito Serrote, indicam a ocorrência expressiva de rochas proterozócas nas nessa região visto que ainda não foram datadas rochas do Grupo Rio do Coco.

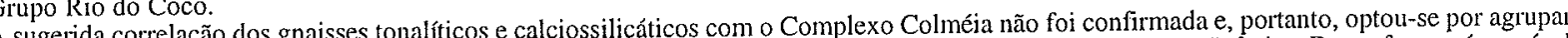

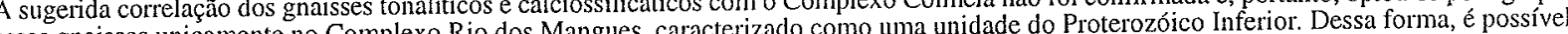
esses gnaisses unicamente no Complexo Rio dos Mangues, caracterizado como uma unidade do Proterozóco lnferior. Dessa forma, e poss que uma parte significativa do segmento crustal do embasamento da porção meridional do Cinturão Araguaia resies sien como remanescentes do colado às rochas arqueanas do Cráton Amazônico durante o Proterozóico Inferior. Interpreta-se os gnaisses sienticos como remanescentes do magmatismo alcalino associado à fase distensiva que gerou, no Proterozóico Médio, a bacia que recebeu os sedimentos do Cinturâo Araguaia. Esse cinturão foi estruturado durante o Ciclo Brasiliano e a idade de $510 \mathrm{Ma}$ publicada para o Granito Matança pode datar a fase final dessa estruturação. Palavras-chcives: Cinturão Araguaia, Geocronologia, Pb-Pb em Zircão.
INTRODUCAO O Cinturão Araguaia situa-se na porção setentrional da Província Estrutural do Tocantins (Almeida et al. 1977) e compreende um conjunto de rochas metassedimentares, que aflora ao longo de aproximadamente 1200 quilômetros seguindo uma direção norte-sul (Fig. 1). A seqüêencia supracrustal metamorfisada varia, de oeste para leste, desde rochas de baixo grau metamórfico até rochas de médio grau, que foram reunidas no Supergrupo Baixo Araguaia (Abreu 1978, Hasui et al. 1984a). Esse cinturão foi estruturado durante o $\mathrm{Ci}$ clo Brasiliano (Moura \& Gaudette 1993a) e separa o Cráton Amazônico dos domínios ocidentais que sofreram as influências desse ciclo durante a evolução do Gondwana. Rochas do embasamento do Cinturão Araguaia afloram no interior de braquianticlinais, no seu segmento setentrional, enquanto que na porção meridional (abaixo do paralelo $10^{\circ} \mathrm{S}$ ) elas não estão confinadas a esse tipo de estrutura (Hasui et al. 1984 a,b, Dall'Agnol et al. 1988).

Estudos geocronológicos realizados por Moura \& Gaudette (1993b) em ortognaisses do interior das estruturas dômicas revelaram que o substrato do Cinturão Araguaia, ao longo de seu segmento setentrional, é arqueano $(2,85 \mathrm{Ga})$ e Paleoproterozóico $(1,85 \mathrm{Ga})$. Dada a similaridade geocronológica e composicional entre esses ortognaisses e os granitóides arqueanos e proterozóicos da porção sudeste da Amazônia oriental, o embasamento do segmento setentrional do Cinturão Araguaia tem sido considerado como uma extensão do Cráton Amazônico (Moura \& Gaudette 1994)
No segmento meridional do Cinturão Araguaia as rochas do embasamento possuem uma área de afloramento significativamente maior, fazendo contato tectônico a leste com as sequiências de alto grau metamórfico do Maciço de Goiás (Hasui et al. 1984a). Os levantamentos geológicos realizados no embasamento dessa porção sul do Cinturão Araguaia permitiram o reconhecimento de pelo menos cinco unidades litoestratigráficas distintas. Essas seqüências foram consideradas inicialmente como sendo de idade arqueana e, pelo menos em parte, correlacionáveis às rochas arqueanas do segmento norte do cinturão, com base em dados estruturais e litológicos (Costa et al. 1983. Hasui et al. 1984a,b). No entanto, a escassez de dados geocronológicos para essas cinco seqüências enfraquece a correlação proposta e dificulta o entendimento tanto do quadro litoestratigráfico interno do embasamento do segmento meridional do Cinturão e o Cráton Amazônico.

Neste trabalho são apresentados os resultados de estudos geocronológicos realizados em rochas gnáissicas do embasamento do segmento meridional (abaixo do paralelo $10^{0} \mathrm{~S}$ ) do Cinturão Araguaia, utilizando o método de evaporação de $\mathrm{Pb}$ em monocristais de zircão ( $\mathrm{Pb}$ - $\mathrm{Pb}$ em zircão). A determinação das idades dessas rochas permitiu definir as relações litoestratigráficas entre algumas unidades do embasamento do segmento sul do Cinturão Araguaia possibilitando ainda melhor compreender a correlação dessas seqüências com aquelas do embasamento aflorantes no seu segmento setentrional. 


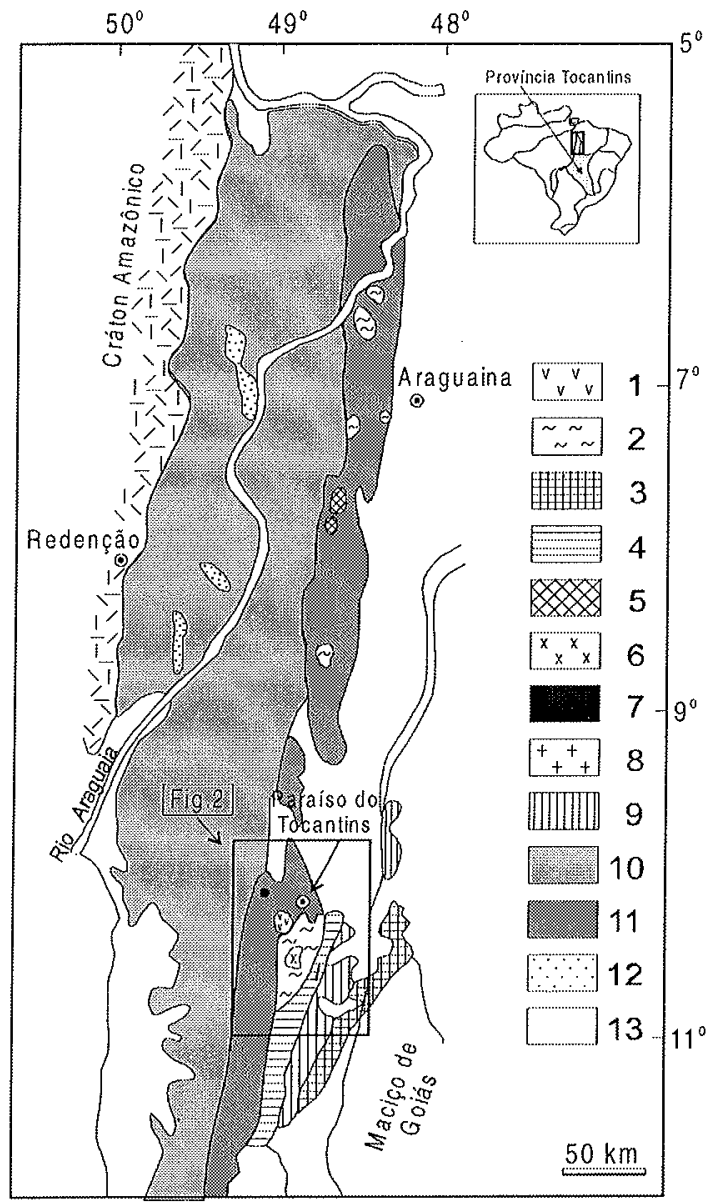

Figura I - Mapa geológico simplificado do Cinturão Araguaia segundo Costa et al. (1988). 1-Grupo Rio do Coco, 2- Complexo Colmeia, 3- Complexo Porto Nacional, 4-Complexo Rio dos Mangues, 5- Gnaisse Cantão, 6-Granito Serrote, 7- Suite Monte Santo, 8- Suite Santa Luzia, 9-Granito Matança, 10-Grupo Tocantins, 11-Grupo Estrondo, 12-Rochas ultramáficas, 13-Sedimentos fanerozóicos, 14-Cráton Amazônico.

CONTEXTO GEOLóGiCo O Cinturão Araguaia (Hasui et al. 1980) está assentado sobre a borda oriental do Cráton Amazônico. Consiste em uma importante unidade geotectônica pertencente à Província Estrutural do Tocantins (ALMEIDA et al. 1977), situando-se em sua porção ocidental. Apresenta-se orientado na direção norte-sul, com um formato alongado atingindo extensão aproximada de 1.200 quilômetros, por até $150 \mathrm{Km}$ de largura. O flanco leste do Cinturăo Araguaia acha-se recoberto por sedimentos fanerozóicos da Bacia do Parnaíba e imediatamente a sudeste faz limite com o Maciço de Goiás (Almeida et al. 1976).

As rochas deste cinturão são representadas por uma sucessão metassedimentar que varia, de oeste para leste, desde rochas de baixo grau metamórfico até rochas de médio grau, enfeixadas no Supergrupo Baixo Araguaia e são entremeadas por rochas vulcânicas básicas a ultrabásicas em forma de sills e diques (Abreu 1978, Abreu et al. 1994, Hasui et al. 1984a).

No segmento norte do Cinturão Araguaia, mais precisamente na sua porção oriental, rochas gnáissicas consideradas como representantes do embasamento, foram agrupadas em duas unidades litoestratigráficas distintas: Complexo Colmeia e Gnaisse Cantão (Costa 1980, Souza et al. 1985, Dall'Agnol et al. 1988). A primeira reúne ortognaisses de idade arqueana $(\approx 2,85 \mathrm{Ga}-\mathrm{Pb} / \mathrm{Pb}$ em zircão) e é constituída predominantemente por gnaisses trondhjemíticos e, secundariamente, por gnaisses tonalíticos e granodioríticos (TTG), além de raros anfibolitos. O Gnaisse Cantão, representado por ortognaisses graníticos, intrude o Complexo Colmeia e seu protólito foi formado no Paleoproterozóico $(\approx 1,85 \mathrm{Ga}-\mathrm{Pb} / \mathrm{Pb}$ em zircão) (Moura \& Gaudette 1993b, Moura \& Gaudette 1999). Esse quadro é muito similar ao que ocorre no Cráton Amazônico onde, TTG's arqueanos são intrudidos por granitos paleoproterozóicos. A similaridade geoquímica entre essas seqüencias do embasamento do Cinturão Araguaia e seus correspondentes cronológicos no Cráton Amazônico adjacente, levaram Moura \&
Gaudette (1994) a sugerir que esta porção do embasamento do Cinturão Araguaia seria uma extensão desse cráton.

No segmento sul do Cinturão Araguaia as rochas do embasamento foram agrupadas por Costa et al. (1983) e Hasui et al. (1984a) em cinco unidades litoestratigráficas consideradas como arqueanas (Fig. 2).

Os gnaisses tonalíticos, graníticos e calciossilicáticos, que apresentam uma estruturação reliquiar leste-oeste, foram correlacionados ao Complexo Colmeia, conforme definido na porção norte do cinturão (Costa 1980). Por sua vez, os gnaisses tonalíticos e calciossilicáticos, associados a quartzitos, micaxistos e anfibolitos, possuindo uma marcante estruturação com direção em torno de $\mathrm{N} 30^{\circ} \mathrm{E}$, foram reunidos na unidade denominada de Complexo Rio dos Mangues (Costa et al. 1983, Hasui et al. 1984b). Gnaisses alcalinos, representados pelos corpos de nefelina-sienito-gnaisses da Serra da Estrela e de Monte Santo foram reunidos na Suíte Monte Santo (Hasui et al. 1984b). O primeiro intrude o Complexo Rio dos Mangues, enquanto o segundo aflora entre os metassedimentos do Supergrupo Baixo Araguaia. Rochas vulcano-sedimentares metamorfisadas na fácies xisto-verde e com foliação de direção leste-oeste, que haviam sido originalmente denominadas de Seqüência Vulcano-Sedimentar do Rio do Coco (Barreira \& Dardenne 1981), foram formalmente reunidas no Grupo Rio do Coco (Costa et al. 1983). Recentemente esta unidade foi investigada geocronologicamente pelo método de $\mathrm{Pb} / \mathrm{Pb}$ em monocristais de zircão e os resultados, ainda preliminares, confirmaram seu posicionamento estratigráfico no Arqueano, com idade de $2.618 \pm 14 \mathrm{Ma}$ (Arcanjo et al. submetido). O Granito Serrote, alojado nas sequêencias gnáissicas correlacionadas ao Complexo Colmeia por Costa et al. (1983), teve igualmente sua idade atribuída ao Arqueano. No entanto ao ser datado pelo método de $\mathrm{Pb} / \mathrm{Pb}$ em zircão revelou uma idade de $1.851 \pm 41$ Ma (Sousa \& Moura 1996).

Adicionalmente, dois corpos de granitóides ocorrem ainda nessa área: o Granitóide Matança, que está em contato tectônico com as seqüências pertencentes ao Maciço de Goiás (Hasui et al. 1984a) (Fig. 1) e, a Suíte Santa Luzia, um grupo de rochas graníticas descritas por Hasui et al. (1984b), que expõe-se em meio à seqüências supracrustais. Uma recente investigação geocronológica realizada por Gorayeb et al. (2000), pelo método de $\mathrm{Pb} / \mathrm{Pb}$ em zircão, revelou, para o Granitóide Matança, uma idade de cristalização de $564 \pm 4 \mathrm{Ma}$. Dados geocronológicos pelo método $\mathrm{Rb} / \mathrm{Sr} \mathrm{em}$ rocha total obtidos por Avelar (1993), revelaram uma idade de $665 \pm 12 \mathrm{Ma}(\mathrm{Ri}=0,70735)$, representativa de uma idade mínima de cristalização para estas rochas.

METODOS ANALÍTICOS Os estudos geocronológicos pelo método de evaporação de $\mathrm{Pb}$ em monocristais de zircão ( $\mathrm{Pb}-\mathrm{Pb}$ em zircão) foram desenvolvidos no Laboratório de Geologia Isotópica do Centro de Geociências da Universidade Federal do Pará - Pará-Iso. As rochas selecionadas para este estudo pertencem a três unidades litoestratigráficas distintas, reconhecidas originalmente por Costa et al. (1983) e Hasui et al. (1984b) e consideradas de idade arqueana (Costa et al. 1983, Hasui et al. 1984b, Costa 1985, Hasui \& Costa 1990 e Abreu et al. 1994). Dessa forma foram coletados: 1) ortognaisses granodioríticos e gnaisses calciossilicáticos, considerados como representantes do Complexo Colmeia; 2) gnaisses tonalíticos, agrupados no Complexo Rio dos Mangues e 3) gnaisses sieníticos da Serra da Estrela, possivelmente relacionados à Suíte Monte Santo.

A separacão de zircão foi realizada a partir de concentrados de minerais pesados que foram obtidos pela pulverização e bateamento das rochas e posterior peneiramento nas frações granulométricas inferiores a $0,35 \mathrm{~mm}$.

Os concentrados de minerais pesados foram submetidos inicialmente a tratamento com bromofórmio. A fração pesada sofreu, em seguida, separação magnética com um separador Frantz Isodynamic. Foram selecionados, preferencialmente, para análise geocronológica, os cristais da fração não magnética (NM) obtidos com $20^{\circ}$ de inclinação longitudinal e $0^{0}$ de inclinação lateral, com uma corrente de 1,5 ampéres. Eventualmente, na ausência dessa fração, teve-se que analisar zircões da fração magnética $(\mathrm{M})$ a $0^{\circ}$, ou não magnética com $1^{\circ}$ de inclinação lateral.

Após limpeza com $\mathrm{HNO}_{3}(50 \%)$, os cristais de zircão foram triados com o auxílio de uma lupa binocular. Os cristais selecionados para datação foram aprisionados em um filamento simples de rênio, em formato de canoa, e a composição isotópica do $\mathrm{Pb}$ foi determinada utilizando um espectrômetro de massa VG ISOMASS 54E equipado com um detetor Daly (fotomultiplicador).

O método de datação aplicado consiste na determinação da idade aparente ${ }^{207} \mathrm{~Pb} /{ }^{206} \mathrm{~Pb}$ de um único cristal de zircão. A razão ${ }^{207} \mathrm{~Pb} /{ }^{206} \mathrm{~Pb}$ é obtida através da evaporação de $\mathrm{Pb}$ do zircão em sucessivas etapas de aquecimento. Cada incremento de temperatura é representado por um 


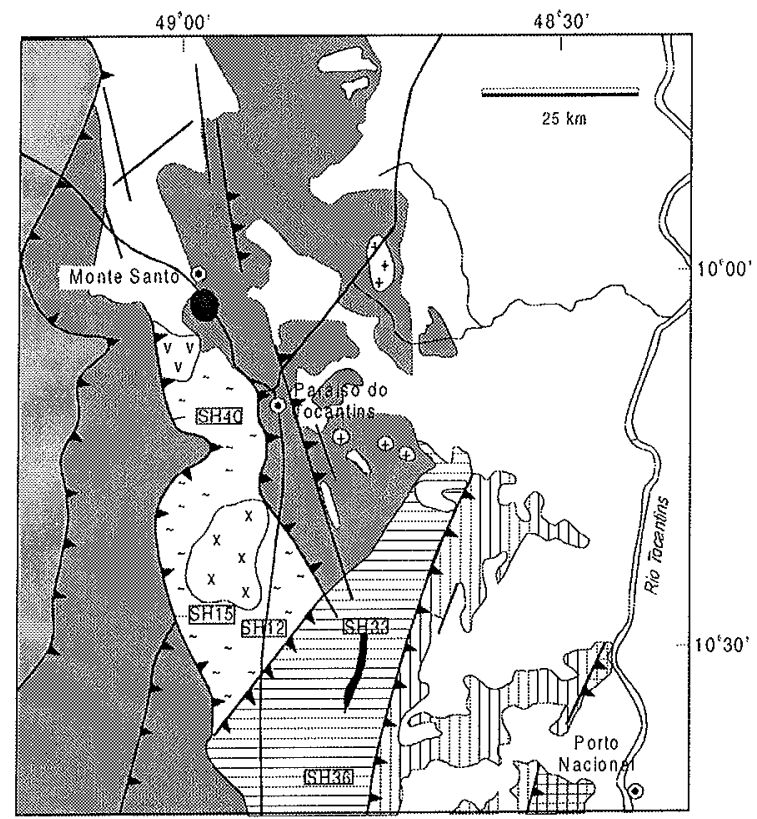

Figura 2 - Mapa geológico simplificado da região de Paraíso do Tocantins segundo Costa et al. (1983). Amostras datadas são representadas pelo prefixo SH. A legenda encontra-se na figura $I$.

conjunto (bloco) de 6 razōes ${ }^{207} \mathrm{~Pb} /{ }^{206} \mathrm{~Pb}$. A média das razões ${ }^{207} \mathrm{~Pb} /$ ${ }^{206} \mathrm{~Pb}$ de cada bloco obtido, com aumentos sucessivos de temperatura, é plotada no diagrama idade versus etapas de aquecimento. Ao final da análise do $\mathrm{Pb}$ evaporado diretamente do zircão, os blocos de razões ${ }^{207} \mathrm{~Pb} /{ }^{206} \mathrm{~Pb}$ de mais altas temperaturas, em geral, tendem a formar um platô de idades, o qual corresponde à composição isotópica do $\mathrm{Pb}$ evaporado das porções mais retentivas da estrutura cristalina do zircão. Correções do $\mathrm{Pb}$ comum $\left({ }^{204} \mathrm{~Pb}\right)$ foram feitas mediante uso do modelo de evolução do $\mathrm{Pb}$ em estágio duplo proposto por Stacey \& Kramers (1975).

No Pará-Iso são adotados alguns critérios metodológicos visando à interpretação das idades aparentes ${ }^{207} \mathrm{~Pb} /{ }^{206} \mathrm{~Pb}$ obtidas (Gaudette $e t$ al. 1998). Entre eles, destacamos os seguintes:

1) Obtenção de sinal de $\mathrm{Pb}$ suficientemente intenso, duradouro e estável para que se possa definir um platô de idade a partir de pelo menos 5 blocos de razões isotópicas ${ }^{207} \mathrm{~Pb} /{ }^{206} \mathrm{~Pb}$.

2) As razões isotópicas ${ }^{204} \mathrm{~Pb} /{ }^{206} \mathrm{~Pb}$ desses blocos devem ser inferiores a 0,0004 para tornar mínima a correção de $\mathrm{Pb}$ de contaminação ou inicial.

A aplicação do método $\mathrm{Pb}-\mathrm{Pb}$ em monocristais de zircão, utilizando filamento simples, tem sido discutida por Gaudette et al. (1993), Macambira et al. (1994) e Moura et al. (1996). Uma descrição detalhada do procedimento experimental do método, incluindo o tratamento estatístico dos resultados e a interpretação dos mesmos encontra-se em Gaudette et al. (1998).

RESULTADOS Ao longo desse trabalho foram datados zircões de cinco rochas das sequiências do embasamento do Cinturão Araguaia. Das rochas tidas como integrantes do Complexo Colmeia, foram selecionados um ortognaisse granodiorítico (SH40) e um gnaisse calciossilicático (SH12) com seu leucossoma de composição granodiorítica (SH15), enquanto que do Complexo Rio dos Mangues, foram datados zircões de um gnaisse tonalítico (SH36). Um gnaisse sienítico (SH33) da Serra da Estrela foi selecionado como representante da Suíte Monte Santo (Fig. 2). A Tabela 1 apresenta os resultados analíticos

Gnaisse Granodiorítico (SH40) Essa rocha possui coloração cinza clara e é composta mineralogicamente por quartzo, ortoclásio e plagioclásio (An 25), como essenciais, e biotita, moscovita, epidoto, apatita, zircão e opacos, como acessórios. Apresenta fenocristais de plagioclásio com tamanhos variando de 2 a $5 \mathrm{~mm}$. Esses cristais são subautomórficos e, em sua grande maioria, apresentam maclamento do tipo albita.

Os cristais de zircão analisados do gnaisse granodiorítico pertencem às frações $0^{\circ} \mathrm{M}$ e $0^{\circ} \mathrm{NM}$. São cristais predominantemente curtos, subautomórficos, de coloração castanho clara, com arestas levemente corroídas e fraturadas, apresentando ainda algumas inclusões. Foram

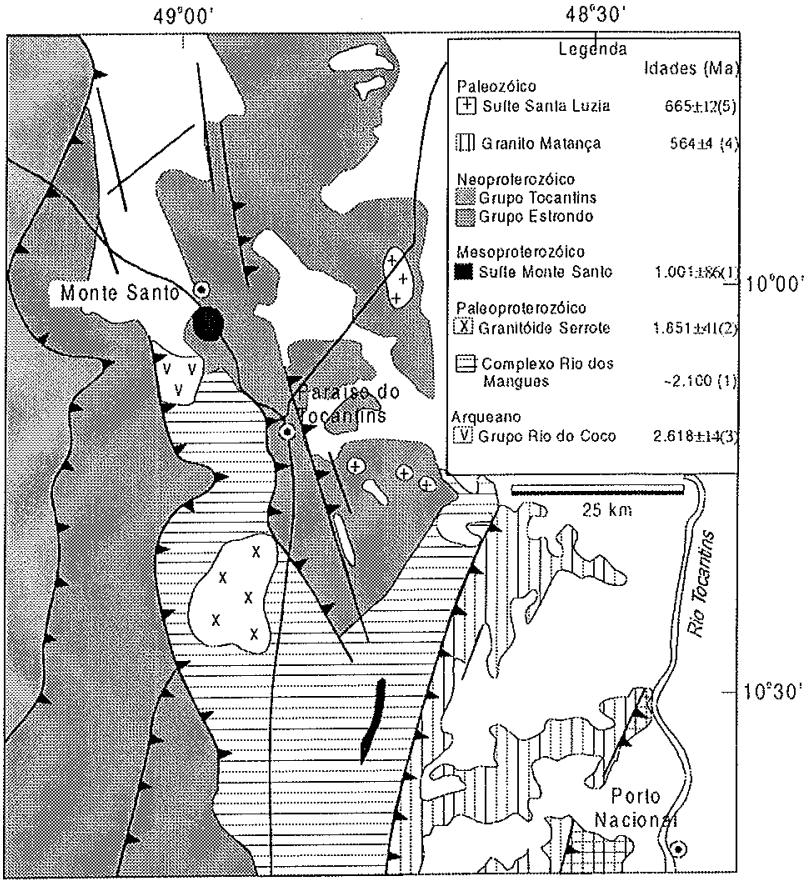

Figura 3 - Mapa geológico simplificado da regiäo de Paraíso do Tocantins, modificado de Costa et al. (1983). Incorporação de rochas conhecidas como Complexo Colmeia no Complexo Rio dos Mangues. Ao lado, proposta estratigráfica suscinta para as unidades do enbasamento, na região de Paraíso do Tocantins, modificada de HASUI et al. $(1981,1984 b)$ e COSTA (1985). Idades segundo: (I) Souza \& Moura (1996); (2) Sousa \& Moura (1995); (3) Arcanjo et al. (2000); (4) Gorayeb et al. (2000); (5) Avelar (1993).

analisados dezoito cristais, dos quais, nove não forneceram emissão para leitura espectrométrica e um cristal foi eliminado por apresentar número de blocos inferior a 5 . Nos 8 zircões restantes, 128 blocos de razões ${ }^{207} \mathrm{~Pb} /{ }^{206} \mathrm{~Pb}$ forneceram uma idade média de $2.014 \pm 36 \mathrm{Ma}$, apesar de apresentarem idades variando entre $1.891 \pm 73 \mathrm{Ma}$ (cristal 5) e $2.126 \pm 77 \mathrm{Ma}$ (cristal 8) (Tab. 1, Fig. 4A).

Gnaisse Calciossilicático (SH12) O gnaisse calciossilicático apresenta granulação grossa sendo que se observa, por vezes, um bandamento desenhado por leitos de minerais máficos de granulação fina, alternados com leitos de agregados quartzo-feldspáticos. Os minerais essenciais são microclínio, plagioclásio (An 28), quartzo, hornblenda, diopsídio e epidoto e os acessórios são titanita, apatita, zircão e opacos; entre os secundários tem-se clorita, moscovita e carbonatos. Localmente, tanto alguns minerais máficos (hornblenda, titanita e epidoto), como os félsicos, notadamente o quartzo, cujos grãos fazem contato geralmente por junção tríplice, apresentam textura em mosaico.

No gnaisse calciossilicático, foram separados e analisados 13 cristais de zircão pertencentes à fração $0^{0} \mathrm{NM}$. São zircões bem cristalizados, prismáticos, subautomorfos, alongados e normalmente translúcidos com tonalidades rosadas; possuem fraturas e inclusões e raramente são metamíticos. Do total de cristais de zircão analisados, 10 foram considerados para o cálculo da idade, fornecendo 170 blocos de razões ${ }^{207} \mathrm{~Pb} /{ }^{206} \mathrm{~Pb}$ e uma idade média de $2.083 \pm 27 \mathrm{Ma}$. Similarmente à amostra anterior, existe uma variação significativa nas idades ${ }^{207} \mathrm{~Pb} /$ ${ }^{206} \mathrm{~Pb}$ obtidas que variaram entre $2.012 \pm 20 \mathrm{Ma}$ (cristal 11) e $2.200 \pm$ $26 \mathrm{Ma}$ (cristal 6) (Tab. 1, Fig. 4B).

O leucossoma granodiorítico (SH15) do gnaisse calciossilicático possui coloração rosada e é composto mineralogicamente por quartzo, microclínio e plagioclásio (An 21) como essenciais, e biotita, moscovita, epidoto, apatita, zircão e opacos como acessórios. Texturalmente destacam-se fenocristais de feldspato potássico com dimensões superiores a $5 \mathrm{~mm}$, levemente orientados. O leucossoma pode exibir foliação incipiente, desenhada pela orientação de quartzo, moscovita e feldspato.

Os cristais de zircão do leucossoma analisados são pequenos, subautomorfos, alongados e normalmente metamíticos, com bordas corroídas; pertencem à fração $1^{\circ}$ magnética $\left(1^{\circ} \mathrm{M}\right)$, pois não foram obtidos cristais de zircão nas frações $0^{\circ} \mathrm{NM} \mathrm{e} 0^{\circ} \mathrm{M}$. Foram analisados dezesseis cristais de zircão, dos quais oito não forneceram emissão para leitura espectrométrica. Dois cristais foram eliminados, um por 
apresentar um erro muito grande sobre a idade $(2194 \pm 285 \mathrm{Ma})$ e o outro por mostrar uma dispersão muito grande dos blocos em relação à média. A idade foi, portanto, calculada com 6 zircões, obtendo-se 128 blocos de razões ${ }^{207} \mathrm{~Pb} /{ }^{206} \mathrm{~Pb}$, que forneceram uma idade média de $1.811 \pm 32 \mathrm{Ma}$ (Tab. 1, Fig. 4C).

Gnaisse Tonalítico (SH36) O gnaisse tonalítico é uma rocha cinza escura e, como característica marcante, apresenta-se extremamente migmatizado. Mineralogicamente é constituído de plagioclásio (An 32), quartzo, biotita, alanita, epidoto, zircão, apatita, titanita, moscovita e poucos opacos. Os cristais de alanita encontram-se metamitizados e cristais secundários de epidoto encontram-se normalmente em contato com o plagioclásio. Em lâmina delgada a rocha exibe textura xenoblástica e, localmente, apresenta grande quantidade de lamelas de biotita normalmente cloritizadas, orientadas e definindo uma foliação. Esta, por sua vez, é paralela ao bandamento, desenhado pela alternância de leitos máficos e félsicos.

No gnaisse tonalítico os cristais de zircão analisados pertencem à fração $0^{0} \mathrm{NM}$ e são translúcidos, prismáticos, automorfos a subautomorfos, longos, normalmente fraturados e com inclusões. Quatorze grãos de zircão foram analisados, porém, desses, 6 não apresentaram emissão para a análise espectrométrica e 2 foram eliminados porque 0 número de blocos de razões ${ }^{207} \mathrm{~Pb} /{ }^{206} \mathrm{~Pb}$ era inferior a 5 .

As análises dos seis cristais de zircão restantes não permitiram a definição de uma idade platô, pois constatou-se um padrão de crescimento contínuo das razões ${ }^{207} \mathrm{~Pb} /{ }^{206} \mathrm{~Pb}$, com o aumento da temperatura de análise, resultando em idades variando desde $500 \mathrm{Ma}$ até valores superiores a 2.000 (Fig. 4D). A grande variação nos resultados das análises produz um erro elevado nas idades e, neste caso, a idade média obtida não tem significado geológico. As idades da ordem de 2.000
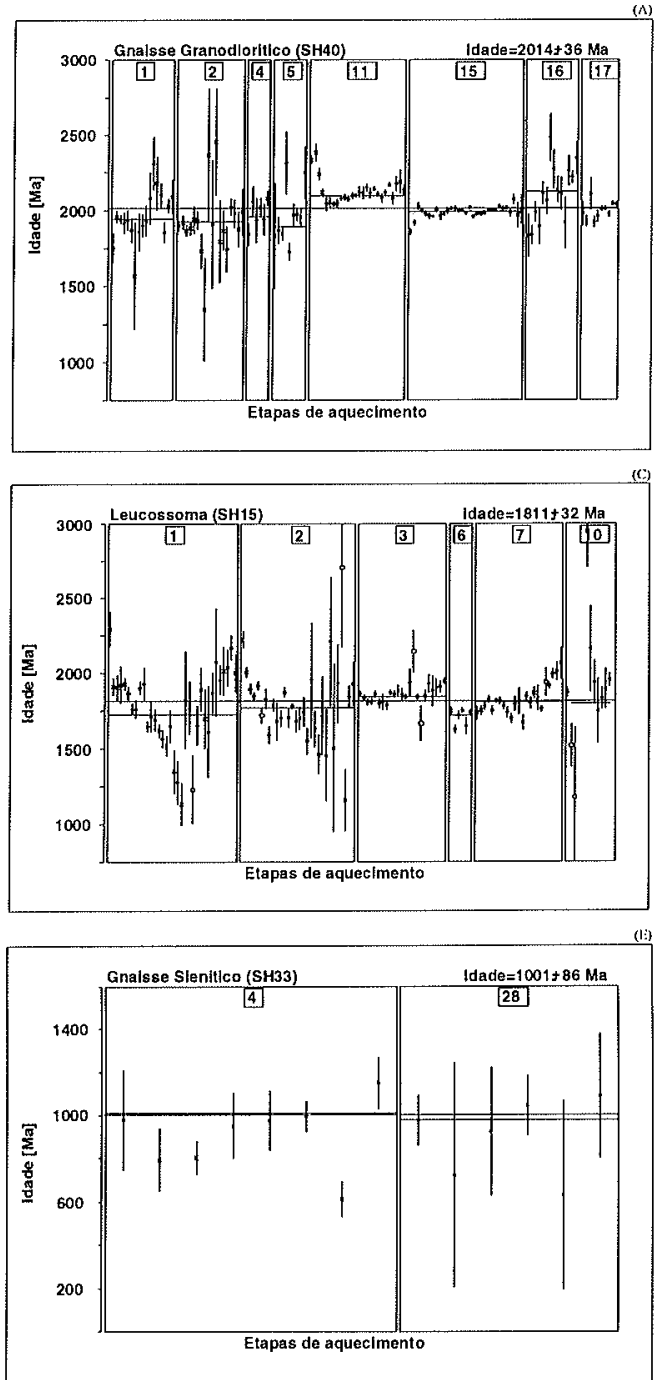

Ma obtidas nos blocos com mais elevadas temperaturas de evaporação, são interpretadas como idades mínimas de cristalização dos zircões (Tab. 1).

Gnaisse Sienítico (SH33) O gnaisse sienítico associado ao corpo de nefelina gnaisse da Serra da Estrela é caracterizado por uma coloração rosa predominante, destacando-se cristais orientados de feldspato que se intercalam com leitos acinzentados constituídos de minerais máficos. Mineralogicamente é constituído por cristais de albita, microclínio, titanita, aegirina-augita, biotita e opacos automorfos (magnetita). Essa rocha possui granulação média com tamanho dos grãos em torno de $2 \mathrm{~mm}$. A textura varia de granoblástica, principalmente entre os agregados de álcali-feldspato até xenoblástica onde normalmente predominam os cristais de plagioclásio.

Os cristais de zircão do gnaisse sienítico são curtos, automorfos a subautomorfos, algo translúcidos, com muitas inclusões e bastante metamíticos, prevalecendo a tonalidade caramelo. Foram separados e analisados 32 cristais de zircão da fração $0^{\circ} \mathrm{NM}$, dos quais 11 não emitiram $\mathrm{Pb}$ suficiente para leitura espectrométrica. Dos 21 cristais de zircão restantes, somente dois foram aproveitados para a obtenção da idade por terem gerado número de blocos das razões ${ }^{207} \mathrm{~Pb} /{ }^{206} \mathrm{~Pb}$, igual ou superior a cinco, após a correção do $\mathrm{Pb}$ de contaminação. Nos dois zircões que participaram do cálculo da idade foram lidos 11 blocos de razões ${ }^{207 \mathrm{~Pb}}{ }^{206} \mathrm{~Pb}$ (Tab. 1), que forneceram uma idade média de 1.006 $\pm 86 \mathrm{Ma}$ (Fig. 4E). Os demais zircões não aproveitados mostraram uma tendência para idades levemente inferiores ou próximas de 1.000 Ma.

DISCUSSÃO As idades aparentes ${ }^{207} \mathrm{~Pb} /{ }^{206} \mathrm{~Pb}$ obtidas pelo método de evaporação de $\mathrm{Pb}$ em monocristais de zircão têm sido interpre-
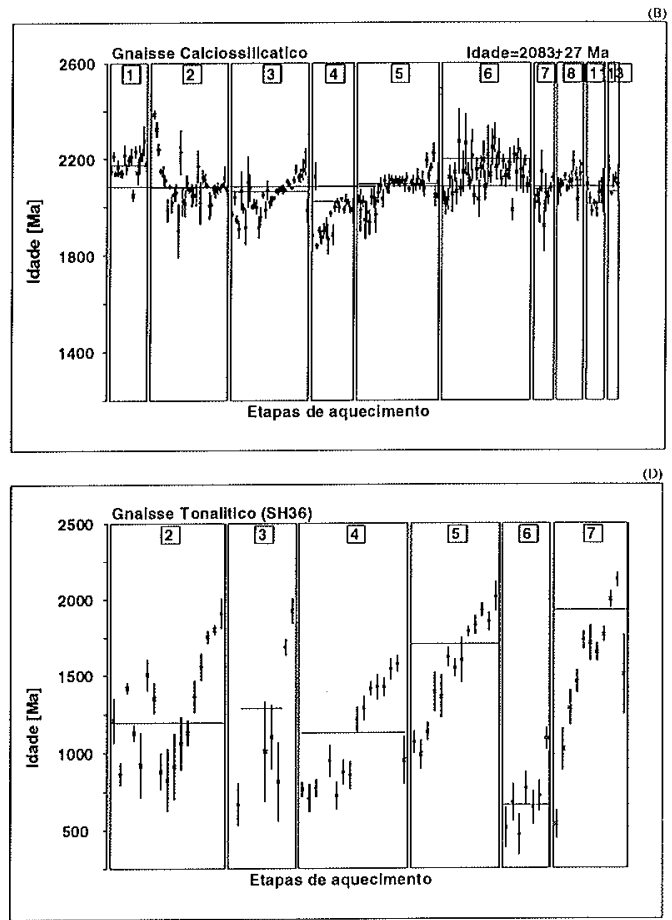

$x$ - blocos eliminados do cálculo da idade devido à razão ${ }^{200} \mathrm{~Pb} /{ }^{204} \mathrm{~Pb}$ ser menor que 2500 .

- - blocos de razões ${ }^{207} \mathrm{~Pb} / 206 \mathrm{~Pb}$ que entraram no cálculo estatístico da idade.

0 - blocos eliminados do cálculo da idade por estarem afastados mais de $2 \sigma \mathrm{em}$ relação a idade média do zircão.

- blocos eliminados manualmente do cálculo da idade por apresentarem valores crescentes ou decrescentes da razão ${ }^{207} \mathrm{~Pb} /{ }^{206} \mathrm{~Pb}$.

— - Idade média. ___ - Idade média de cada zircão.

Figura 4 - Diagramas representando a idade (ordenada) versus etapas de aquecimento (abcissa), das rochas gnáissicas da região de Paraiso do Tocantins, pelo método Pb/Pb em zircão. (A) 8 cristais de zircão pertencentes a gnaisses granodiorítico; $(B) 10$ cristais de zircão pertencentes a gnaisse calciossilicáti. (C) 6 cristais de zircão pertencentes a leucossoma granodiorítico associado a gnaisse calciossilicático; (D) 6 cristais de zircão pertencentes a gnaisse tonalitico; (E) 2 cristais de zircão pertencentes a gnaisse sienítico. 
tadas como idades mínimas de cristalização do zircão (Kober 1987), embora, tenha sido demonstrado por diversos autores que essas idades podem se superpor, nos limites dos erros analíticos, às idades obtidas pelo método U/Pb em monocristais polidos de zircão (Kröner et al. 1996, Karabinus \& Gromet 1993, Kröner et al. 1994).

Utilizando a técnica do filamento simples, Moura et al. (1996) e Gaudette et al. (1998) demonstraram que as idades aparentes ${ }^{207} \mathrm{~Pb} /$ ${ }^{206} \mathrm{~Pb}$ de monocristais de zircão podem ser ligeiramente mais jovens que as idades $\mathrm{U} / \mathrm{Pb}$ convencionais em zircão de rochas ígneas não deformadas ou levemente deformadas. No entanto, essas idades em geral se superpõem dentro dos limites dos erros analíticos. Dessa forma, as idades aparentes ${ }^{207} \mathrm{~Pb} /{ }^{206} \mathrm{~Pb}$ apresentadas neste trabalho são interpretadas como idades mínimas de cristalização dos cristais de zircão. Entretanto, acredita-se que essas idades, dentro dos limites dos erros analíticos, possam estar muito próximas da idade verdadeira de cristalização desse mineral

A idade aparente ${ }^{207} \mathrm{~Pb} /{ }^{206} \mathrm{~Pb}$ de $2.014 \pm 36 \mathrm{Ma}$ (Fig. 3A) obtida nos zircões do gnaisse granodiorítico é interpretada como idade mínima de cristalização desses minerais. Dá-se preferência a esta interpretação sobretudo pelo fato de existir uma variação considerável nas idades dos cristais de zircão (Tab. 1). Dessa forma, essa idade média indica uma idade mínima de cristalizacão do protólito ígneo desse ortognaisse uma vez que o sistema U/Pb em zircão é robusto o suficiente para preservar essa informação (Page \& Bell 1985, Evans \& Fisher 1986, Fanning et al. 1988). A aceitação dessa hipótese implica na existência de um evento magmático transamazônico acrecionário na região estudada, muito embora inexistam dados Sm/Nd para comprovar esta hipótese.

O significado atribuído para a idade de $2.083 \pm 28 \mathrm{Ma}$ (Fig. 4B), obtida em zircões do gnaisse calciossilicático, depende da interpretação da origem dos cristais de zircão analisados. $O$ fato desses cristais provirem de uma rocha metassedimentar abre a possibilidade dos zircões terem se formado durante o metamorfismo que atingiu a rocha ou constituírem grãos detríticos. No primeiro caso, os zircões teriam se formado durante processos metamórficos ligados ao Ciclo Transamazônico. Evidências nesse sentido foram encontradas por Gorayeb (1996) que determinou idades $\mathrm{Rb}-\mathrm{Sr}$ em rocha total em rochas de alto grau metamórfico da região de Porto Nacional. As razões iniciais $(\sim 0,701)$ são bastante baixas em quase todas as isócronas de granulitos máficos $(2.010 \pm 98 \mathrm{Ma})$ e enderbitos $(2.182 \pm 153 \mathrm{Ma})$ exceto nos kinzigitos $(1.925 \pm 121 \mathrm{Ma})$, com $\mathrm{RI}=\sim 0,704$. Essas idades foram interpretadas como indicadoras da idade mínima para os principais processos metamórficos e deformacionais atuantes na região. Alternativamente, no caso dos zircões serem detríticos, o resultado obtido poderia indicar a idade da rocha fonte da sedimentação, ou seja, os zircões seriam provenientes do retrabalhamento através de um ciclo sedimentar de rochas formadas em torno de 2.100 Ma. Nesse caso, essa idade também estabeleceria o tempo máximo da sedimentação da rocha calciossilicática.

A idade de $1.818 \pm 34 \mathrm{Ma}$ fornecida pelos zircões do leucossoma granodiorítico (Fig, 4C) associado à rocha calciossilicática merece uma discussão cautelosa visto que os cristais analisados são metamíticos, provenientes da fração $1^{0} \mathrm{M}$, o que pode levar a obtenção de idades ${ }^{207} \mathrm{~Pb} /{ }^{206} \mathrm{~Pb}$ bem menores que a real. Essa rocha foi afetada pela deformação relacionada com a instalação do Cinturão Araguaia, durante o Ciclo Brasiliano e o grau mais acentuado de metamitização desses cristais de zircão, pode ter favorecido a abertura do sistema U$\mathrm{Pb}$, causando perda parcial de $\mathrm{Pb}$. Não obstante, a idade obtida pode estar relacionada à influência do magmatismo que gerou o Granito Serrote datado de $1.851 \pm 41 \mathrm{Ma}$ (Sousa \& Moura 1996). A proximidade dessa amostra com esse corpo granítico (Fig. 2) reforça essa interpretação.

Os cristais de zircão analisados do gnaisse tonalítico (SH36) mostraram um padrão crescente das razões ${ }^{207} \mathrm{~Pb} /{ }^{206} \mathrm{~Pb}$, que forneceu idades variando de 500 a $2.000 \mathrm{Ma}$. Esse tipo de padrão pode indicar uma mistura de duas fases causada, por exemplo, por um sobrecrescimento de uma borda mais jovem em um núcleo de idade mais antiga. Feições de sobrecrescimento foram encontradas em grãos de zircão da amostra datada, examinados em microscópio petrográfico. Como essa rocha apresenta-se intensamente migmatizada, é possível argumentar que esse sobrecrescimento estaria relacionado a essa migmatização, muito provavelmente de idade brasiliana. Admite-se, portanto, que as idades em torno de 2,0 Ga (Fig. 4D), obtidas a mais altas temperaturas para os zircões analisados, representariam idades mínimas de cristalização para esse gnaisse tonalítico.

O gnaisse sienítico ( $\mathrm{SH} 33$ ), associado aos gnaisses alcalinos da Serra da Estrela, forneceu uma idade ${ }^{207} \mathrm{~Pb} / 206 \mathrm{~Pb}$ em zircão de $1.001 \pm$ $86 \mathrm{Ma}$ (tab. 1, Fig. 4E), que foi interpretada como idade mínima de cristalização para essa rocha. Essa interpretação sugere que os gnaisses alcalinos, incluídos na Suíte Monte Santo, representariam um magmatismo alcalino do final do Mesoproterozóico, que marcaria a fase distensiva do processo de formação do Cinturão Araguaia. Magmatismos alcalinos dessa idade estão ligados a tafrogênese no período Toniano, que resultou na fragmentação do Supercontinente Rodínia (Hoffman 1991). No Brasil, evidências desse evento distensivo têm sido encontradas na Amazônia (Bittencourt et al. 1999), bem como na Província Borborema (Brito Neves \& Fuck 1999) e no Cráton São Francisco (Machado \& Noce 1993).

Os dados geocronológicos apresentados neste trabalho revelam uma expressiva ação do Ciclo Transamazônico na área estudada, contrapondo-se a concepção anterior de se tratar de um substrato essencialmente de idade arqueana (Costa et al. 1983, Hasui et al. 1984a, Costa 1985, Hasui \& Costa 1990, Abreu et al. 1994). As amostras SH12, SH15 e SH40 são provenientes de áreas originalmente correlacionadas ao Complexo Colmeia, de idade arqueana, conforme definido no segmento setentrional do Cinturão Araguaia. Portanto, a sugerida extensão da área de ocorrência dessa unidade litoestratigráfica para a porção sul do embasamento do Cinturão Araguaia não é sustentada pelos dados geocronológicos.

O gnaisse tonalítico (amostra SH36), coletado na área mapeada como Complexo Rio dos Mangues, também foi formado mais provavelmente no Paleoproterozóico. Consequentemente, a idade arqueana

Tabela I - Resultados analíticos Pb/Pb por evaporação em zircão de rochas gnáissicas da regiäo de Paraíso do Tocantins.

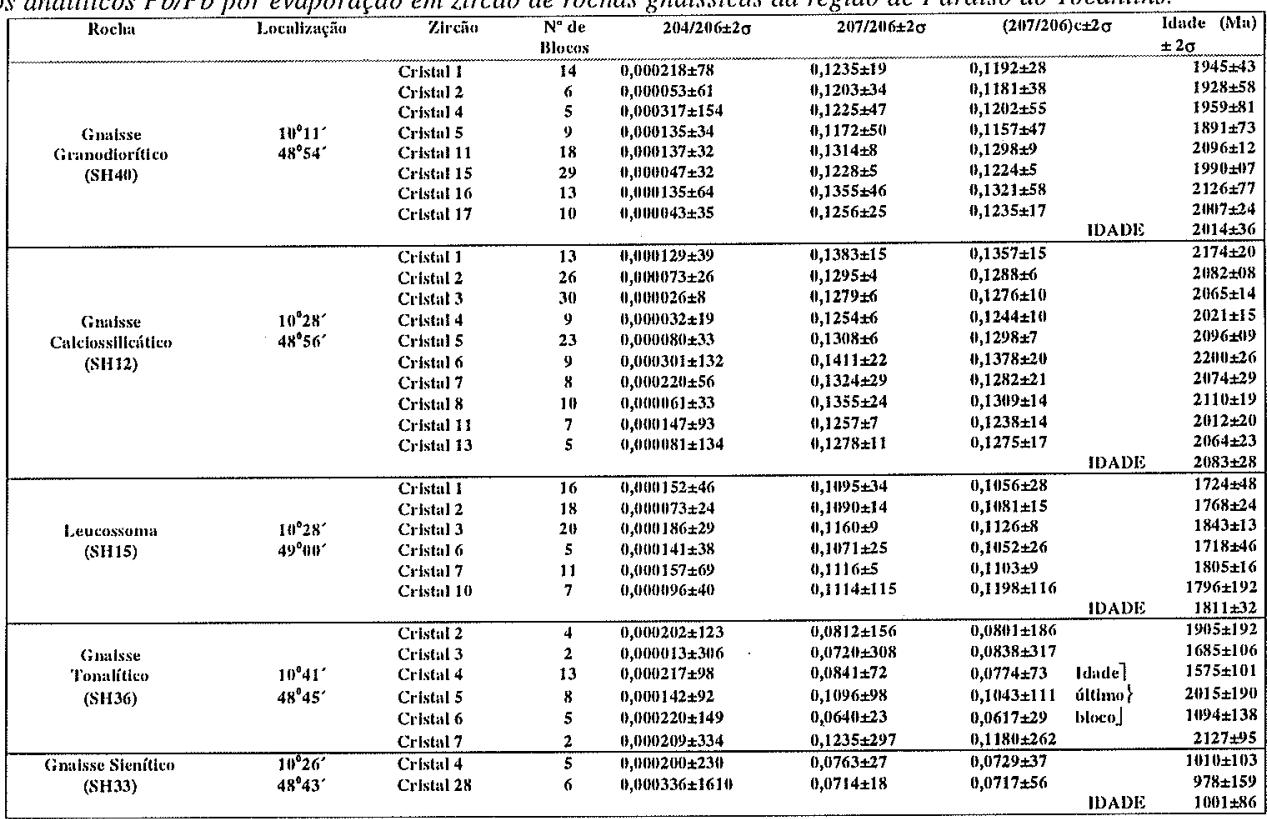


sugerida para esta unidade é igualmente questionável com base nesse dado geocronológico. Da mesma forma, a idade do gnaisse sienítico (amostra SH33) permite descartar a idade arqueana sugerida para a Suíte Monte Santo.

No que concerne às rochas do embasamento do Cinturão Araguaia, a única similaridade registrada entre as porções norte e sul desse cinturão é a presença de corpos graníticos intrusivos do Paleoproterozóico, deformados no ciclo Brasiliano. No segmento norte, essas rochas são representadas pelo Gnaisse Cantão, com idade $\mathrm{Pb}$ $\mathrm{Pb}$ em zircão de $1,85 \mathrm{Ga}$ (Moura \& Gaudette 1993b, Moura \& Gaudette 1999). Na porcão sul ocorre o Granitóide Serrote cuja datação pelo método de $\mathrm{Pb}-\mathrm{Pb}$ em zircão, indicou uma idade mínima de cristalização para esse corpo de $1.851 \pm 41 \mathrm{Ma}$ (Sousa \& Moura 1996). Não se sabe, no entanto, se o contexto tectônico em que se alojou esse batólito era similar àquele em que se formou o protólito do Gnaisse Cantão, seu contemporâneo no segmento norte do Cinturão Araguaia.

Os dados geocronológicos aqui apresentados e aqueles disponíveis na literatura sugerem que o embasamento da porção sul do Cinturão Araguaia pode ser considerado como um terreno distinto daquele que constitui o embasamento da porção norte desse cinturão. No segmento norte, o embasamento é caracterizado por rochas de idade arqueana (Complexo Colmeia), intrudido por granitóides do Paleoproterozóico (Gnaisse Cantão) e é entendido como sendo uma extensão do Cráton Amazônico (Moura \& Gaudette 1994). Contrariamente, o embasamento do segmento meridional do Cinturão Araguaia é constituído, predominantemente, de rochas do Paleoproterozóico, sendo que a existência de rochas de idade arqueana não foi ainda confirmada, embora faltem dados geocronológicos por outros métodos e datações complementares em rochas vulcano-sedimentares do Grupo Rio do Coco. Consequentemente, propõe-se neste trabalho um novo ordenamento litoestratigráfico para as rochas do embasamento do segmento sul do Cinturão Araguaia.

Nesta proposta, pelo fato de não existirem dados geocronológicos para o Grupo Rio do Coco, ainda manteve-se essa unidade como a única possível representante do Arqueano na área. Devido a não comprovacão da existência de rochas gnáissicas de idade arqueana, foi abolida a sugerida correlação dos complexos gnáissicos da área estudada com o Complexo Colmeia (Moura \& Souza 1996). Em função disso, optou-se pela expansão do termo Complexo Rio dos Mangues para agrupar as rochas gnáissicas estruturadas no Paleoproterozóico. Ao final do Paleoproterozóico, alojou-se nas rochas gnáissicas do Complexo Rio dos Mangues, o Granito Serrote, datado de 1,85 Ga (Sousa \& Moura 1996). No Mesoproterozóico se alojaram as rochas da Suíte Monte Santo, provavelmente relacionadas ao processo de rifteamento responsável pela formação da bacia que resultou na deposicão dos sedimentos do Supergrupo Baixo Araguaia. Finalmente, no Cíclo Brasiliano, ligado ao processo de estruturação do Cinturão Araguaia, houve a colocação do Granitóide Matança, cuja idade $\mathrm{Pb} / \mathrm{Pb}$ em zircão é de $564 \pm 4 \mathrm{Ma}$ (Gorayeb et al. 2000).

CONCLUSÕES Os dados geocronológicos apresentados neste trabalho revelam uma expressiva ocorrencia de rochas de idade proterozóica na área estudada, contrapondo-se a concepção anterior de se tratar de um substrato essencialmente de idade arqueana. Tanto as amostras SH12, SH15 e SH40, que são provenientes de áreas originalmente correlacionadas ao Complexo Colmeia, como a amostra SH36, coletada na área mapeada como Complexo Rio dos Mangues, possuem idades ${ }^{207} \mathrm{~Pb} /{ }^{206} \mathrm{~Pb}$ paleoproterozóicas. Da mesma forma, a idade de $1001 \pm 86 \mathrm{Ma}$ do gnaisse sienítico (amostra SH33) permite descartar a idade arqueana sugerida para a Suíte Monte Santo.

Agradecimentos Este trabalho é parte da dissertação de mestrado da primeira autora e contou com o apoio do CNPq através da concessão de uma bolsa de estudo (OF. N ${ }^{0} 216 / 93$-CPGG). O apoio financeiro concedido pela UFPA através do Curso de pós-graduação em Geologia e Geoquímica foi fundamental para a realizaçấo dos trabalhos de campo no Estado do Tocantins. A dois revisores anônimos da RBG pela análise crítica do origional.

\section{Referências}

Abreu F.A.M. 1978. O Supergrupo Baixo Araguaia. In: SBG, Congresso Brasileiro Gcologia, 30, Recile, Anais, 2: 539-545.

Abreu F.A.M., Goraycb P.S.S. Hasui Y. 1994. Tectônica c Inversão Melamórica no Cinturão Araguaia. In: SBG, Simpósio Geologia Amazônja, 4, Belćm, Resumos Expandidos, 1-4.
Almeida F.F.M., Hasui Y., Neves B.B.B., Futck R.A. 1977. Províncias Estruturais Brasilei'ss. In:

\section{SBG, Simpósio Geologia Nordeste, 8, Campinal Grande, Alas, 363-39}

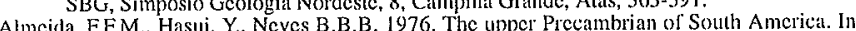
Boletim do Instituto de Geociências da USP. 7:45-80.

Arcanjo S.H.S., Moura C.A.V.; Abrcu F.A.M., Gornycb P.S.S. 2000. Rio do Coco Group: a 2. cxolic terrain in the Palcoproterozoic Tocantins Shear Belt, Central Brazil. In: SBG, Congresso Internacional de Gcologia, 31 , Rio de Janciro, (In Press).

Avelar V.G. dc. 1993. Estudo Perrográfico c Petrológico da Suítc Santa Luzia, região de Paraíso do Norte - Tocantins. Universidade Federal do Parḱ. Centro de Gecciências. Belém, Trabalho de Conclusão de Curso, $36 \mathrm{p}$.

Barradas J.A.S., Lafon J.M., Kotschoubcy B. 1992. Gencronologia $\mathrm{Pb}-\mathrm{Pb}$ e Rb-Sr da região do Monte do Carmo - Porto Nacional. TO. Novos resultados. In: SBG, Congresso Brísilcir Gcologia, 37, São Paulo, Anais, 2: 182-183.

Baturcira C.F. \& Dardenne M.A. 1981. Sequiência vulcano-scdimentar do Rio do Cooo. In: SBG Simpósio de Gcologia do Centro-Ocsic, 1, Goiânia, Atas, 241-264.

Brito Neves B.B. \& Fuck R.A.1999. From Rodinia to Westen Gondwana: An approach to the Brasiliano-Pan African Cycle and orogenic collage. Epixodes, 22(3): 155-165.

Costa J.B.S. 1980. Estratigralia da regiano de Colméia. In: SBG, Congresso Brasilciro Gcologia, 31 Camboriú, Anais, 2:720-728.

Costa J.B.S. 1985. Aspectos lito-cstruturais c cvolução crustal da região centro notte de Goiás. Universidade Federal do Pará. Centro de Geociências. Belém, Tese de Doutoramento, $209 \mathrm{p}$.

Costa J.B.S., Goraycb P.S. de S., Bermeguy R.L., Gama Ji. R., Kolschoubey B., Lemos R.L. 1983. Projclo Paraiso do Nortc; relatório final. Bclém, UFPA. Centro de Geociências. $125 \mathrm{p}$.

Custa J.B.S., Hasui Y., Gorayeb P.S.S. I 988. Cinturāo Araguaia.. In: SBG, Congresso Brasilcir Geologia, 35, Belém, Rolciro de Excursōes, 71-92

Dall'agnol R., Teixcira N.P., Macambira J.B., Kotschoubcy B., Goraych P.S.S., Santos M.D. 1988. Petrologia dos Gnaisscs c Micaxistos da porçãon norte da Faixa de Dobramentos AraguaiaGO - Brasil. In: SBG, Congresso Latino Amcricano Gcologia, 7, Bclcm, Anais, 1:1-9.

Evan K.V. \& Fisher L. B. 1986. U-Pb gechronology of Iwo augen gneiss terains, ldaho-new dat and tectonic implications. Conditu Journal of Earth Science, 23:1919-1927.

Fannin C.M. Flint R.B., Parker A.J., Ludwig K.R., Blissel A.H. 1988. Refined Proterozoic cvolution of the Gawler Craton, South Australlia, through U-Pb zircon gecochronology. Precambrian Research 40/41:363:386.

Gaudcut H.E, Lafon J.M., Moura C.A.V., Scheller T. 1993. Datą̧ão de monocristais de zircão por cvaporaç̃̃o de $\mathrm{Pb}$ no Laboratório de Geologia Isolópica - UFPA: metodologia c primeiros cris

Gaudelc HE, Laton J.M. Moura C.A.V., Scheller T. 1998. Comparision of single filament $\mathrm{Pb}$ crapo craporation/ionization zircon agcs with conventional U-Pb rcsults: cxamples

Goraycb P.S.S. 1996. Petrologia c cvolução crustal das rochas de alto grau de Porto Nacional - TO Universidade Fcderal do Pará. Centro de Geciências. Belém, Tese de Doutoramento, $258 \mathrm{p}$.

Goraycb P.S.S., Moura C.A.V., Arcanjo S.H.S. 2000. Granitogenesis cvents in the Porto Nacional Paln - Paraiso do Tocantins region, Tocantins Province, Brazil, In: SBG, Congresso - Palmals - Paraiso do Tocantins region, Tocantins Province

Hasui Y \& Costa J.B.S. 1990. O cinturão Araguaia: Um novo cnloguc cstrutural-cstratigrálico. In SBG, Congresso Brasileiro Geologia, 36, Natal, Anais, 6:2535-2549.

Hasu Y Costa JB S. Abrcu FA.M 1984a. Província Tocantins. In: Hasui Y. \& Almeida F.A.M. O Pré-Cambriano do Brasil. São Paulo, Edgar Blucher. p. 187-204.

Hasui Y. Costa J.B.S., Gorayeb P.S.S., Lemos R.L., Gama Jr. T., Bemerguy R.L. 1984b. Geologia do Pró-Cambriano da regão de Paraíso do Norte de Goís-GO. In: SBG, Congresso Bratsilciro Gcologia, 33, Rio de Janciro, Anais, 2220-2233.
Hosui Y, Tassinari C.C.G., Siga Ji. O., Tcixcila W., Almeida F.F.M., Kawalshita K. 1980. Dalações Rh-S. c K-Ar do centro norte do Brasil c scu signilicado gcológico-geoteclônjeo. In: SBG Congresse Brasitciro Gcologia, 31. Camboriú, Anais, 5:2659-2667.

Hortman P.F. 1991. Did the breakout of Laurentia turn Gondwanaland inside ont? Science 252:1405-1412.

Kambinus P \& Gromet L. P. 1993. Aplications of single-grain zircon cvaporation analyses 10 decrital main studics and age discrimination in igncous suiles. Geochimica Cosmochimica Acta, $57: 4252 \cdot 4267$

Koher B 1087 Singlc Grain Evaporation Combined with Pb Emilter Bedding ${ }^{207} \mathrm{~Pb} /{ }^{206} \mathrm{~Pb}$ Investigations using Thermal lon Mass Spectrometry and Implications to Zirconology. Contribution Mineralogy aud Petrology, 96.63-71.

Krïner A., Jacckel P., Williams I.S. 1994 . Pb-loss palterns in zircons from a high-grade metamorphic terain as icvealced by different dating incthods: $\mathrm{U}-\mathrm{Pb}$ and $\mathrm{Pb}-\mathrm{Pb}$ ages $\mathrm{for}$ Anctamorphic terrain as rcvealcd by different dating methods: $\mathrm{U}-\mathrm{Pb}$ and $\mathrm{Pb}-\mathrm{Pb}$ ages 5 . igl.

Kröner A., Hegner E., Wendt J.I., Byerly G.R. 1996. The oldest part of the Barberton granitoid grecnstonc torrain, South Africa: cvider

Macambir J B Moura C A.V Laton J.M. Sucller T 1994.0 mélodo $\mathrm{Pb}-\mathrm{Pb}$ por Evaporatão $\mathrm{cm}$ Zircão: Avaliação dos Dados Oblidos no Laboralório de Geologia Isolópica da UFPA. In: SBG, Congresso Brasilciro Gcologia, 38, Camboriú, Anais, 404-406.

Machado N \& Noce CM 1923. A cvolucão do sctor sul do cráton do São Francisco cntre 3.1 0,5 Ga bascada em ycocronologia U-Pb. In: Simpósio sobre o Crílon do São Francisco, 2 Salvador, Amais, $100-102$

Mour CA.Y \& Gaudette HE 1993a. Evidence of Brasiliano/Panalfican deformation in the Araguaia Botl Implication for Gondwana cyolution In' Revista Brasteira de Geociencios 23(2):117-123

Moura C.A.V. \& Gaudette H.E. 1993b. Zireon Ages of the Basement Orthogneisses of the Alaguaia Bclt, North - Central Brazil. In: SBG, Congresso Brasilciro Geoquímica, 4, Briślial, Resumos Expandidos, 232-234.

Mour"1 CAV \& Gaudeuc HE 1994 Geochemistry of the bascment orthouncisses of the Araguaia Belt, Tocantins-Brazil. In: SBG, Congresso Brasilciro Gcologia, 38, Camboriú, Anais. 2:240-241.

Moura C.A.Y. \& Gaudelte H.E. 1999. Zireon ages of basement orthogneisses from the northern scement of the Araguaia BelL, Brazil. A. K. Sinha (cd,), Basement Tectonics, 13:155-178.

Moura C.A.V., Gaudelte H.E., Macambira M.J.B., Lalon J.M., Schelleı T. 1996. Datação do monocristais de zireão por cvaporaça de Pb cm filamento simples: comparação com rosultados U-Pb. In: SBG, Contesso Brasilciro Geologia, 39, Salvador, Anais, 6:480-483.

Moura C.A.V. \& Souza S.H.P. 1996. Síntese dos dados Geccronológicos das rochas do Embasumento do Cinturão Araguaia c suas Implicaç

Page R.W \& B Il T.H. 1985. Isotopic and structural responses of grnites to successive deformation and mclamorphism. Jounal of Geology, 94:365-379.

Souza A.C.C. Dall agnol R. Teixcira N.P. 1985. Perrologia do Gnaisse Cantão: Implicacôcs na Faixa de Dobramento Araguaia Scra do Estrondo-GO. Revista Brasileira de Geociências $15: 300-310$.

C. A 1996. Estudo Geocronológico do Granito Scirotc, Paráso do Tocantins. In: SBG, Congresso Brasilciro Gcoquímica, 5, Nitcroi, Anais, CD-ROM.

Souza S.H.P. de. 1996 Gcologia c Geocronologia da Região a sul de Paráso do Tocantins. Universidade Federal do Pará Centro de Gcociências. Belém, Disscltação de Mestrado, $127 p$.

Stacey J.S. \& kramers J.D. 1975. Aproximation of Terrestrial Lead Isolope Evolution by 1 wo-Stagc Modd Earth Planetary Science Letters, 26(2):207-221.

Windley B.F. 1984. The Evolving Continents. 2 cd. New York, Great Britain. 399 p.

Manuscrito A-1116

Recebido em 25 de agosto de 1999

Revisão dos autores em 10 de julho de 2000 Revisão aceita em 15 de julho de 2000 